\title{
Intoxicação por amônia em bovinos que receberam uréia extrusada ou granulada: alterações em alguns componentes bioquímicos do sangue
}

\author{
Alexandre Coutinho \\ ANTONELLI ${ }^{1}$ \\ Gabriel Adrian Sanches \\ TORRES ${ }^{1}$ \\ Clara Satsuki MORI ${ }^{1}$ \\ Pierre Castro SOARES 2 \\ Celso Akio MARUTA ${ }^{1}$ \\ Enrico Lippi ORTOLANI ${ }^{1}$
}

\section{Correspondência para:}

Alexandre Coutinho Antonelli, Faculdade de Medicina Veterinária e Zootecnia Departamento de Clínica Médica, Av. Prof. Dr. Orlando Marques de Paiva, 87 - Cidade Universitária - 05508-000 SãoPaulo-SP, alexvet@usp.br

Recebido para publicação: 03/08/2007 Aprovado para publicação: 28/08/2008

\author{
1 - Departamento de Clínica Médica da Faculdade de Medicina Veterinária e \\ Zootecnia da Universidade de São Paulo, São Paulo-SP \\ 2 - Departamento de Medicina Veterinária da Universidade Federal Rural de \\ Pernambuco, Recife-PE
}

\section{Resumo}

Doze garrotes Girolando nunca alimentados com uréia foram distribuídos em dois grupos de seis animais cada, e induzidos a desenvolver um quadro de intoxicação por amônia através da administração de uréia extrusada ou granulada em dose única $(0,5 \mathrm{~g} /$ $\mathrm{kg}$ PV). Foram determinados no plasma ou soro os teores de amônia, glicose, L-lactato, uréia e creatinina, além do volume globular em sangue total nos seguintes momentos: antes da administração de uréia, no surgimento dos tremores, após o primeiro episódio convulsivo, e após 240 minutos do início do experimento. A hiperamoniemia ocorreu a partir dos primeiro tremores. Maiores glicemia e lactemia-L foram constatadas no momento do ápice da intoxicação (episódio convulsivo), os quais foram superiores ao tempo basal. A produção endógena de uréia aumentou no decorrer do experimento devido à hiperamoniemia $(r=0,57)$, atingindo seus valores mais altos ao término do experimento. Quanto maior foi o teor de amônia, maiores foram as concentrações de lactato-L, glicose, uréia, creatinina e volume globular. Estes resultados permitem concluir que o grau de hiperamoniemia aumentou a gliconeogênese, a glicólise anaeróbica, a síntese de uréia endógena e o grau de desidratação. Entre as variáveis estudadas os teores de glicose e de lactato-L foram os melhores indicadores para monitorar alterações bioquímicas na intoxicação pela amônia.

\section{Introdução}

A proteína é o principal limitante para ruminantes criados extensivamente, principalmente no período de seca, pois este nutriente apresenta-se em menores teores nas gramíneas de clima tropical ou subtropical. ${ }^{1}$ A utilização de fontes de nitrogênio nãoprotéico, como suplementação protéica para bovinos criados em condições extensivas, é reconhecida como procedimento a ser adotado na nutrição de ruminantes há mais de um século ${ }^{2}$, em substituição a alimentos industrializados protéicos (soja, algodão, glúten de milho, refinasil, etc). Embora os alimentos ricos em proteína sejam de melhor
Palavras-chaves:

Uréia.

Amônia.

Bovinos.

Intoxicação.

Alterações bioquímicas. qualidade nutricional do que as fontes de nitrogênio não-protéico, os primeiros são mais caros e destinados ao consumo humano, optando-se assim pelo uso de substratos nitrogenados, em especial a uréia, subproduto do petróleo e muito disponível em nossas condições. No Brasil, mais de 20 milhões de bovinos são suplementados com uréia anualmente, principalmente durante o período seco. ${ }^{3}$

O uso de uréia proporciona várias vantagens na alimentação de ruminantes, embora sua utilização inadequada possa trazer sérios danos à saúde animal devido à sua potencial toxicidade. $\mathrm{Na}$ verdade, a intoxicação nos ruminantes não é pela uréia, 
mas sim pela amônia gerada do primeiro composto através da fermentação ruminal. ${ }^{4}$ A presença de surtos de intoxicação por amônia é o principal obstáculo para que seu uso rotineiro seja adotado por mais criadores. ${ }^{5}$ Apesar de ser esporádica nos rebanhos, a intoxicação por amônia apresenta quadro clínico drástico, rápido e na maioria das vezes devastador, podendo levar bovinos à morte em até 30 minutos após a sua ingestão. ${ }^{6,7}$

A uréia ingerida é rapidamente hidrolisada no rúmen em compostos amoniacais $\left(\mathrm{NH}_{4}^{+}\right.$e $\left.\mathrm{NH}_{3}\right)$, pela urease bacteriana. Enquanto que o amônio $\left(\mathrm{NH}_{4}^{+}\right)$ é hidrossolúvel e não absorvível pela parede ruminal a amônia é lipossolúvel e altamente absorvível. ${ }^{6}$ Assim, condições que favoreçam o surgimento de $\mathrm{pH}$ alcalino como jejum, dieta rica em fibra e/ou com baixo teor de carboidratos solúveis ou mesmo a ingestão de quantidades consideráveis de uréia predispõem à intoxicação por amônia em ruminantes, por aumentar e acelerar a absorção de amônia para a corrente sangüínea. ${ }^{8}$ A maior parte da amônia absorvida é transformada rapidamente no fígado com a síntese de uréia, através do ciclo da uréia. Entretanto, quando há aumento na produção e absorção de amônia ocorre uma sobrecarga no sistema hepático, e, como conseqüência, aumento nos teores de amônia no sangue. ${ }^{8,9}$ No ambiente intracelular a amônia bloqueia o ciclo de Krebs, por meio do bloqueio por saturação do sistema glutamina-sintetase, resultando em diminuição da produção de energia, e finalmente inibição da respiração celular.

Os sintomas da intoxicação por uréia são: desconforto, apatia, tremores musculares e fasciculações, salivação excessiva, dejeções (fezes e urina) freqüentes, respiração rápida e difícil, desidratação incoordenação, vocalização, enrijecimento dos membros, prostração, decúbito, tetania, meteorismo gasoso, midríase, nistagmo, convulsão, e conseqüentemente morte. ${ }^{7,10,11}$

O diagnóstico de intoxicação por amônia é realizado com base no histórico de ingestão de grandes quantidades de fonte de NNP, associado à presença de sintomas característicos, e à determinação laboratorial da concentração de amônia no sangue ou líquido ruminal.

O objetivo deste estudo foi avaliar e comparar o efeito provocado em alguns componentes bioquímicos sangüíneos em bovinos que apresentassem quadro clínico grave de intoxicação por amônia por ingestão de uréia granulada ou extrusada.

\section{Material e Método}

Foram utilizados 12 bovinos Girolando, machos, hígidos, providos de cânulas ruminais, e com $200 \mathrm{~kg}$ de peso vivo. Os animais foram mantidos em baias individuais e receberam uma dieta basal contendo teores relativamente baixos de proteína bruta $(10 \%)$, sem qualquer suplementação com nitrogênio não-protéico, composta de feno de capim coast-cross e concentrados energéticos por um período de no mínimo 30 dias. Suplemento mineral foi oferecido ad libitum. Esta dieta foi oferecida na quantidade de matéria seca equivalente a $2,2 \%$ do peso vivo. Cada animal foi utilizado apenas uma vez no experimento.

Os animais foram distribuídos aleatoriamente em dois grupos, de seis animais cada, de acordo com os seguintes tratamentos: o grupo 1 recebeu 2,5 g/ $\mathrm{kg}$ de peso vivo (P.V.) de uréia extrusada (C) TORTUGA Companhia Zootécnica Agrária) contendo $20 \%$ de uréia e $80 \%$ de farelo de milho; e o grupo 2 recebeu $0,5 \mathrm{~g} /$ $\mathrm{kg}$ P.V. de uréia granulada (Petrofértil ${ }^{\circledR}$ ) e $2,0 \mathrm{~g} / \mathrm{kg}$ P.V. de farelo de milho, separadamente. Ambos os grupos receberam quantidades equivalentes de uréia e farelo de milho. Quinze horas antes do início da intoxicação os animais foram mantidos sem alimentação, com exceção de água de bebida, a fim de aumentar o pH ruminal e predispor à presença do quadro tóxico. Após este período, a uréia, extrusada ou não, assim como o farelo de milho foram administrados pela cânula ruminal dos animais, por meio de sonda plástica de 
grosso calibre.

Quando os animais apresentaram quadro convulsivo foram tratados por meio de esvaziamento do conteúdo ruminal, por meio de sondagem, via cânula ruminal, e com tratamento sistêmico preconizado por Ortolani, Mori e Rodrigues Filho. ${ }^{7}$

As amostras de sangue foram colhidas da veia jugular externa, antes da administração de uréia, no surgimento dos tremores, após o primeiro episódio convulsivo, e após 240 minutos do início do experimento. Amostras sangüíneas foram colhidas em tubos de colheita à vácuo Vacutainer $^{\mathbb{R}}$ ), sem anti-coagulante para as determinações de uréia, creatinina e lactatoL (utilizando-se kits diagnóstico SIGMA n 555, Bayer ${ }^{\circledR} \mathrm{n}^{\circ}$ T-011821-56, e SIGMA n 735-10, respectivamente); outras amostras sangüíneas foram colhidas em tubos contendo EDTA (ácido etilenodiaminotetracético, sal dissódico) para determinar amônia plasmática (kit Raichem ${ }^{\circledR} \mathrm{n}^{\circ}$ 85444), e do volume globular que, para o qual, utilizou-se o sangue total acondicionado em tubos capilares de $75 \mathrm{~mm}$, próprios para microhematócrito, e centrifugados a $13000 \mathrm{G}$ por 5 minutos; e frascos contendo fluoreto de sódio para a determinação de glicose (kit SIGMA $\mathrm{n}^{\circ}$ 315-100).

Os dados foram analisados utilizando ANOVA e as médias foram comparadas utilizando-se o teste de Duncan. No estudo de relação entre duas variáveis foram utilizados análise de regressão linear e coeficiente de correlação. Foram consideradas diferenças significativas quando $p$ foi inferior a 0,05 . Considerou-se um coeficiente de correlação como de intensidade alta quando $r>0,6$; média se $0,3<\mathrm{r}<0,6$ e baixa no caso de $\mathrm{r}<0,3^{12}$.

\section{Resultados}

No início de cada procedimento experimental, os garrotes apresentavam-se saudáveis, alertas e ativos. Apenas um bovino do grupo 1 apresentou discretas fasciculações, recuperando-se prontamente, enquanto que um animal do grupo 2 ficou apático, teve tremores musculares, apresentou incoordenação motora, ficou em decúbito lateral, mas não teve nenhum episódio convulsivo, recuperando-se posteriormente sem seqüelas. Os demais animais apresentaram vários sintomas característicos de intoxicação por amônia, sendo que os tremores musculares iniciaram-se $6025 \mathrm{e}$ $79 \pm 26$ min após a administração de uréia nos grupos 1 e 2 , respectivamente, enquanto que os episódios convulsivos manifestaramse $95 \pm 42$ e $160 \pm 66$ min após o fornecimento de uréia aos grupos 1 e 2, respectivamente.

Os teores de amônia plasmática elevaram-se marcadamente nos dois grupos, sendo que no grupo 1 atingiu seus valores mais altos no momento da convulsão (1626士 $285 \mathrm{mmol} / \mathrm{L})$, enquanto que no grupo 2 esses teores mais elevados ocorreram já no surgimento dos tremores musculares (Tabela 1). Em relação aos teores de uréia sérica, em ambos os grupos obtiveram-se os valores mais altos no final do experimento $(7,26 \pm 1,94 \mathrm{mmol} / \mathrm{L} \mathrm{e} 7,14 \pm 1,59 \mathrm{mmol} /$ $\mathrm{L}$, para o grupo 1 e 2 respectivamente) em relação ao início do experimento, ou seja, após 240 minutos da administração da uréia (Tabela 1). Em relação aos teores de creatinina sérica, foi observado que no grupo 1 os valores elevaram-se já no surgimento dos episódios convulsivos (265土 $23 \mathrm{mmol} /$ L), enquanto que no grupo 2 esses valores foram mais altos apenas ao término do experimento $(252 \pm 24 \mathrm{mmol} / \mathrm{L})$ (Tabela 1). Os teores de lactato-L foram em ambos os grupos superiores, em relação ao tempo basal, no momento do surgimento dos episódios convulsivos (22,40 \pm 6,73 $\mathrm{mmol} / \mathrm{L}$ e $18,30 \pm 3,87 \mathrm{mmol} / \mathrm{L}$, para o grupo 1 e 2 respectivamente) (Tabela 1). Quando avaliadas as concentrações plasmáticas de glicose, verificou-se que houve aumento gradativo de seus teores em ambos os grupos, atingindo o pico de hiperglicemia no momento em que surgiram os primeiros episódios convulsivos $(13,70 \pm 2,82 \mathrm{mmol} /$ $\mathrm{L}$ e $11,70 \pm 2,39 \mathrm{mmol} / \mathrm{L}$, para o grupo $1 \mathrm{e}$ 2 respectivamente) (Tabela 1 ). Na avaliação do volume globular, foi constatado que no 
Tabela 1 - Valores médios e desvio padrão de amônia e glicose plasmáticas, uréia, creatinina e lactato-L séricos, e o volume globular de bovinos intoxicados por amônia que receberam uréia extrusada (Grupo 1) ou uréia granulada (Grupo 2) - São Paulo - 2002

\begin{tabular}{|c|c|c|c|c|c|}
\hline \multirow{2}{*}{$\begin{array}{l}\text { Variável } \\
\text { analisada }\end{array}$} & \multirow{2}{*}{ Grupo } & \multicolumn{4}{|c|}{ Momentos } \\
\hline & & início & tremores & convulsão & após $240 \mathrm{~min}$ \\
\hline \multirow{2}{*}{$\begin{array}{c}\text { Amônia } \\
\text { plasmática } \\
(\mu \mathrm{mol} / \mathrm{L})\end{array}$} & 1 & ${ }^{\prime} 28 \pm 16$ & ${ }^{b} 1005 \pm 127$ & a $1626 \pm 285$ & a $1507 \pm 391$ \\
\hline & 2 & ${ }^{b} 31 \pm 11$ & a $1140 \pm 269$ & a $1574 \pm 216$ & a $1307 \pm 474$ \\
\hline \multirow{2}{*}{$\begin{array}{l}\text { Uréia sérica } \\
(\mathbf{m m o l} / \mathrm{L})\end{array}$} & 1 & $\mathrm{~b}_{4,20 \pm 1,67}$ & ab $5,78 \pm 2,05$ & ab $6,84 \pm 2,31$ & a $7,26 \pm 1,94$ \\
\hline & 2 & ${ }^{b} 4,04 \pm 1,34$ & ab $5,72 \pm 1,11$ & ab $6,28 \pm 1,22$ & a $7,14 \pm 1,59$ \\
\hline \multirow{2}{*}{$\begin{array}{l}\text { Creatinina sérica } \\
(\mu \mathrm{mol} / \mathrm{L})\end{array}$} & 1 & ${ }^{b} 215 \pm 17$ & ${ }^{b} 225 \pm 8$ & $2265 \pm 23$ & a $272 \pm 12$ \\
\hline & 2 & ${ }^{b} 201 \pm 19$ & $\mathrm{ab} 223 \pm 31$ & $\mathrm{ab} 244 \pm 26$ & $a_{252}=24$ \\
\hline \multirow{2}{*}{$\begin{array}{l}\text { Lactato-L sérico } \\
(\mathrm{mmol} / \mathrm{L})\end{array}$} & 1 & ${ }^{b} 2,31 \pm 1,01$ & b $7,44 \pm 4,65$ & ${ }^{a} 22,40 \pm 6,73$ & a $20,97 \pm 9,02$ \\
\hline & 2 & ${ }^{b} 1,43 \pm 1,14$ & ${ }^{b} 6,10 \pm 1,99$ & $\mathrm{a} 18,30 \pm 3,87$ & a $18,56 \pm 6,66$ \\
\hline \multirow{2}{*}{$\begin{array}{c}\text { Glicose } \\
\text { plasmática } \\
(\mathbf{m m o l} / \mathrm{L})\end{array}$} & 1 & ${ }^{c_{4} 4,39 \pm 0,24}$ & b $8,23 \pm 1,98$ & ${ }^{a} 13,70 \pm 2,82$ & ${ }^{a} 14,73 \pm 5,48$ \\
\hline & 2 & ${ }^{\circ} 4,22 \pm 0,20$ & b8 $8,05 \pm 1,59$ & a $11,70 \pm 2,39$ & ${ }^{a} 12,57 \pm 1,35$ \\
\hline \multirow{2}{*}{$\begin{array}{c}\text { Volume globular } \\
(\%)\end{array}$} & 1 & b $34 \pm 4$ & ab $37 \pm 4$ & $a 43 \pm 5$ & $a 43 \pm 6$ \\
\hline & 2 & $b_{34}=5$ & $32 \pm 4$ & $46 \pm 2$ & $a 48 \pm 5$ \\
\hline
\end{tabular}

grupo 1 ocorreu aumento apenas após o

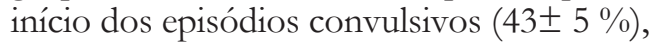
enquanto que no grupo 2 atingiu seus valores mais altos já no surgimento dos tremores

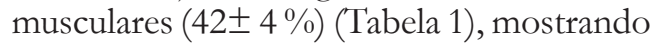
desidratação progressiva em casos de intoxicação por amônia. Não ocorreram diferenças significativas entre os grupos em nenhuma das variáveis estudadas.

Quando estudada a relação entre as variáveis, verificou-se que quanto maiores foram os teores de amônia plasmática maiores foram as concentrações de uréia ( $\mathrm{r}$ $=0,57)$, creatinina $(\mathrm{r}=0,64)$, lactato- $\mathrm{L}(\mathrm{r}=$ $0,82)$, glicose $(r=0,75)$ e volume globular $(r$ $=0,77)$. Também foi observado que quanto maior o volume globular, maior os teores de creatinina $(\mathrm{r}=0,62)$ e lactato- $\mathrm{L}(\mathrm{r}=0,69)$, assim como maior o teor de creatinina sérica, maior a concentração de lactato- $\mathrm{L}(\mathrm{r}=0,53)$.

\section{Discussão}

Neste trabalho, a dose de $0,5 \mathrm{~g}$ uréia/kg PV provocou quadro clínico definitivo de intoxicação por amônia culminando com convulsão em 83\% (10/ 12) dos animais, pois cada um deles foi intoxicado uma única vez, sendo assim menos refratários à toxidez por amônia. No trabalho clássico de Bartley et al. ${ }^{6}$ foram utilizados apenas 26 animais em 244 testes com administração de igual quantidade de uréia utilizada neste experimento $(0,5 \mathrm{~g} / \mathrm{kg} \mathrm{PV})$, sendo obtidos quadros definitivos de intoxicação em apenas 51\% das tentativas. Acredita-se que, nesse supracitado experimento, pelo fato 
dos bovinos haverem sido submetidos a várias intoxicações em série, os animais se tornaram mais resistentes à amônia, por meio do aumento a atividade do ciclo de uréia, tornando-os capaz de transformar mais efetivamente a amônia em uréia. 5,13,14

Por outro lado, os teores de amônia plasmática no surgimento dos tremores foram ao redor de $1100 \mathrm{mmol} / \mathrm{L}(850$ $1597 \mathrm{mmol} / \mathrm{L}$ ) (Tabela 1). Estes valores médios são $93 \%$ superiores aos citados por Bartley et al. ${ }^{6}$ como diagnóstico definitivo $(570 \mathrm{mmol} / \mathrm{L})$, provavelmente porque esses autores interromperam a intoxicação, administrando ácido acético ou removendo todo o conteúdo ruminal com o surgimento dos tremores nos bovinos. Como estes dados têm sido referenciados na literatura clássica existe uma necessidade de revisão da mesma. Além disso, é bastante provável que a discordância dos resultados também esteja ligada à metodologia empregada. Bartley et al. ${ }^{6}$ determinaram a amônia por método de difusão (câmara de Conway), sendo esta técnica considerada de baixa precisão e sensibilidade, onde podem ocorrer perdas significativas de amônia, determinando valores subestimados ${ }^{15}$, diferentemente do presente trabalho, onde as determinações de amônia foram feitas por procedimento enzimático, utilizando "kits" de diagnóstico comerciais, de grande exatidão.

Também se constatou, neste trabalho, que os bovinos apresentavam quadro convulsivo quando os teores de amônia plasmática atingiam valores médios de $1600 \mathrm{mmol} / \mathrm{L}$. Estes resultados são pouco superiores aos descritos por Froslie ${ }^{16}$, que afirmou que o quadro convulsivo surgia entre 880 e $1470 \mathrm{mmol} /$ L. Tais dados foram obtidos também com metodologia de difusão supracitada, devendo assim também ser revistos.

Embora os animais não tivessem sido alimentados com nitrogênio nãoprotéico e recebessem dieta com teores ligeiramente deficientes em proteína bruta existiu um grande aumento na conversão de amônia em uréia no ciclo da uréia. Provavelmente, as concentrações de uréia não foram maiores neste experimento devido a uma possível excreção deste metabólito na urina, já que Kitamura ${ }^{17}$ detectou um grande incremento na excreção urinária de uréia durante a intoxicação por amônia, aumentando assim a capacidade de depuração da uréia sangüínea por no mínimo três horas após o início dos episódios convulsivos.

O teor de lactato- $\mathrm{L}$ aumentou significativamente nos grupos 1 e 2 (Tabela $1)$, sendo mais de duas vezes superiores aos constatados nos experimentos sobre acidose láctica ruminal. ${ }^{18}$ Nesse distúrbio, o lactato é gerado no interior do rúmen, pela excessiva fermentação bacteriana de carboidratos solúveis, e absorvido provocando reconhecida acidose metabólica. O lactato-L foi altamente indicativo dos efeitos deletérios que a amônia provocou no funcionamento do ciclo de Krebs. Quando em excesso, a amônia se combina com o a-ceto-glutarato deixando de formar o succinato e produzir ATP. ${ }^{4}$ Desta maneira, a célula passa o obter parte de sua energia pela via glicolítica anaeróbica, com geração terminal de lactato-L.

Os teores de creatinina sérica se elevaram bem acima dos valores de referência (até 65\% superiores), nos grupos 1 e 2 (Tabela 1), em especial quando se instalava a convulsão. Como existiu uma correlação positiva entre a elevação do volume globular e da creatinina $(r=0,62)$ pode-se deduzir que a desidratação provocou menor fluxo sangüíneo aos rins provocando uma menor filtração glomerular e conseqüente incremento na creatinina sérica. Com a instalação do estado de desidratação, concluiu-se também que houve diminuição na circulação sangüínea nos órgão menos essenciais e periféricos diminuindo assim o aporte de oxigênio aos tecidos, levandoos a aumentar a produção de energia por meio da via glicolítica anaeróbica. ${ }^{11}$ De fato, neste trabalho certificou-se de que 
quanto maior o volume globular ou teor de creatinina, maiores os teores de lactato$\mathrm{L}(\mathrm{r}=0,69$ e $\mathrm{r}=0,73$, respectivamente).

O aumento do volume globular é a confirmação da ocorrência de desidratação intensa em casos de intoxicação por amônia. A amônia per se é muito irritativa ao trato pulmonar, podendo causar a migração de fluídos para os pulmões resultando em edema pulmonar, que é um achado freqüente em necropsias de animais intoxicados por amônia. ${ }^{16}$ Para Antonelli et al. ${ }^{10}$, grande parte desta desidratação é causada pelo edema pulmonar. Mas outro fator também deve colaborar para este aumento do seqüestro de líquidos do sangue, pois animais que desenvolveram desidratação leve não apresentaram edema pulmonar, sugerindo a realização de maiores estudos para entender melhor a dinâmica dos fluídos sangüíneos na intoxicação por amônia.

Outro indicador da ação do excesso de amônia no organismo foi a glicemia, onde teve seu incremento já no surgimento dos tremores musculares, atingindo seu ápice durante a crise convulsiva e mantendo alta até o término do experimento. Os dados obtidos comprovaram que ocorreu uma alta correlação entre os teores de amônia sangüínea e a glicemia $(r=0,75)$. A glicemia se eleva por várias ações concomitantes, onde o excesso de amônia inibe a liberação da insulina, diminuindo a passagem de glicose para dentro das células, e estimula a glicogenólise hepática causada pela liberação de adrenalina, associado a uma maior produção de glucagon que estimula a rápida produção de glicose no organismo ${ }^{19}$; a desidratação ainda predispõe a uma redução na utilização da glicose por tecidos periféricos ${ }^{20,21}$. Outro fator que pode interferir na utilização da glicose é o diminuto uso deste substrato energético pelas células causado pelo bloqueio do ciclo de Krebs. ${ }^{22}$

Não ocorreram diferenças significativas entre os grupos para todas as variáveis estudadas porque a ingestão de grandes quantidades de uréia, independente de sua apresentação, causa intoxicação por amônia. De acordo com Antonelli ${ }^{23}$, o processo de extrusão não interfere com a velocidade de hidrólise da uréia quando esta é oferecida em grande quantidade, principalmente quando o ambiente ruminal apresenta-se alcalino. Porém o teor de amônia $\left(\mathrm{NH}_{3}\right)$ no rúmen, tanto quantitativo como percentual, é maior em animais que ingeriram uréia granulada devido ao maior $\mathrm{pH}$ do suco ruminal. $\mathrm{O}$ autor ainda especula que o menor $\mathrm{pH}$ ruminal em animais que ingeriram uréia extrusada esteja ligado com a mais rápida digestão do amido extrusado, tornando este substrato mais disponível para a fermentação bacteriana nos primeiros 120 minutos após a ingestão e aumentando a produção de ácidos graxos voláteis. Portanto, ocorre apenas o retardamento no tempo de absorção de amônia derivada da uréia extrusada, postergando o surgimento dos sinais clínicos e todas as alterações decorrentes do quadro tóxico.

\section{Conclusões}

Estes resultados permitem concluir que o grau de hiperamoniemia influenciou positivamente na gliconeogênese, na glicólise anaeróbica e na síntese de uréia. Os teores de glicose e L-lactato foram muito superiores no ápice da intoxicação do que no tempo basal, demonstrando que estas variáveis são mais indicadoras para monitorar alterações bioquímicas causadas pela intoxicação por amônia. As alterações bioquímicas em casos de intoxicação por amônia causadas pela uréia extrusada ou granulada não mostraram diferença entre si.

\section{Agradecimentos}

À FAPESP, pela bolsa concedida (processo no 03/09991-8). 


\section{Ammonia poisoning in cattle fed extruded or prilled urea: alterations in some chemistry components}

\section{Abstract}

Twelve yearling Girolando steers never fed urea before were assigned randomly in two groups of six animals each. In both groups were administered intraruminally a single dose $(0.5 \mathrm{~g} / \mathrm{kg} \mathrm{BW})$ of extruded or prilled urea in order to induce ammonia poisoning. Plasma or serum levels of ammonia, urea, creatinine, glucose, L-lactate were determined. Hematocrit values were also recorded. Blood samples were taken before the administration of urea, at the onset of muscle tremors, at the first convulsive episode, and 240 minutes after the beginning of the urea feeding. Hyperammonemia already occured at the time of the first muscle tremors. Glucose and L-lactate levels were higher at the peak of the intoxication (convulsive episode), which were higher compared to the beginning of the experiment. Endogenous production of urea increased during the experiment due to hyperammonemia $(r=0.57)$, reaching peak levels at the end of the trials. Higher ammonia values lead to increased concentrations of L-lactate, glucose, urea, creatinine and hematocrit values. These results showed that high levels of ammonia increased glyconeogenesis, anaerobic glycolysis, the endogenous synthesis of urea and the level of dehydration. L-lactate and glucose were the best variables to monitor biochemical changes in cases of ammonia poisoning.

\section{Referências}

1 MINSON, D. J. Forage in ruminant nutrition. Queensland: Academic Press, , 1990. 483 p.

2 ARMSBY, H. P. The nutritive value of the non-protein portion of feeding stuffs. United States Department of Agriculture Bureau of Animal Industry Bulletin, n. 139 , p. $49,1911$.

3 KITAMURA, S. S.; ORTOLANI, E. L.; ANTONELLI, A. C. Intoxicação por amônia em bovinos causada pela ingestão de uréia dietética: conceitos básicos e novas descobertas. Revista de Educação Continuada do CRMVSP, v. 5, n. 3, p. 292-298, 2002.

4 HALIBURTON, J. C.; MORGAN, S. E. Nonprotein nitrogen-induced ammonia toxicosis and ammoniated feed toxicity syndrome. Veterinary Clinics of North America: Food Animal Practice, v. 5, n. 2, p. 237-249, 1989.

5 MORRIS, J. G.; PAYNE, E. Ammonia and urea toxicoses in sheep and their relation to dietary nitrogen intake. Journal of Agricultural Science, v. 74, n. 2, p. 259-271, 1970.

6 BARTLEY, E. E.; DAVIDOVICH, A.; BARR, G. W.; GRIFFEL, G. W.; DAYTON, A. D.; DEYOE, C. W.; BECHTLE, R. M. Ammonia toxicity in cattle. I. Rumen and blood changes associated with toxicity and treatments methods. Journal of Animal Science, v. 43, n. 4, p. 835-841, 1976.
Key words:

Urea.

Ammonia.

Bovines.

Poisoning.

Biochemical changes.
7 ORTOLANI, E. L.; MORI, C. S.; RODRIGUES FILHO, J. A. Ammonia toxicity from urea in a Brazilian dairy goat flock. Veterinary and Human Toxicology, v. 42, n. 2, p. 87-89, 2000.

8 DAVIDOVICH, A.; BARTLEY, E. E.; BECHTLE, R. M.; DAYTON, A. D. Ammonia toxicity in cattle. III. Absorption of ammonia gas from the rumen and passage of urea and ammonia from rumen to the duodenum. Journal of Animal Science, v. 46, n. 3, p. 551-558, 1977.

9 O'CONNOR, J. E.; COSTELL, M. New roles of carnitine metabolism in ammonia cytotoxicity. In: GRISOLÍA, S.; FELIPO, V.; MIÑANA, M-D. Advances in experimental medicine and biology. New York: Plenum Press, 1990. v. 272, cap. 12, p. 183-195.

10 ANTONELLI, A. C.; MORI, C. S.; SOARES, P. C.; KITAMURA, S. S.; ORTOLANI, E. L. Experimental ammonia poisoning in cattle fed extruded or prilled urea: clinical findings. Brazilian Journal of Veterinary Research and Animal Science, v. 41, n. 1, p. 67-74, 2004.

11 RADOSTITS, O. M.; GAY, C. C.; HINCHCLIFF, K. W.; CONSTABLE, P. D. Veterinary medicine: a textbook of the diseases of cattle, horses, sheep, pigs, and goats. Philadelphia: Saunders Elsevier, 2007. 2156 p.

12 LITTLE, T. M.; HILLS, F. J. Agricultural experimentation - design and analysis. New York: John Wiley \& Sons, 1978. 350 p. 
13 CHALUPA, W.; CLARK, J.; OPLIGER, P.; LAVKER, $R$. Detoxication of ammonia in sheep fed soy protein or urea. Journal of Nutrition, v. 100, n. 2 p. 170-176, 1970 .

14 PAYNE, J. M.; PAYNE, S. The metabolic profile test. New York: Oxford University Press, 1987. 179 p.

15 PESCE, A. J.; KAPLAN, L. A. Methods in clinical chemistry. Saint Louis: Mosby, 1987. 1366 p.

16 FROSLIE, A. Feed-related urea poisoning in ruminants. Folia Veterinaria Latina, v. 17, n. 7, p. 17$37,1977$.

17 KITAMURA, S. S. Intoxicação por amônia em bovinos e ratos: o desempenho renal na desintoxicação e o emprego de tratamentos alternativos. 2002. 92 f. Dissertação (Mestrado em Clínica Veterinária) Faculdade de Medicina Veterinária e Zootecnia, Universidade de São Paulo, São Paulo, 2002.

18 MARUTA, C. A.; ORTOLANI, E. L. Susceptibilidade de bovinos das raças Jersey e Gir à acidose láctica ruminal: II - acidose metabólica e metabolização do lactato-L. Ciência Rural, v. 32, n. 1, p. $61-65,2002$.

19 VISEK, W. J. Ammonia metabolism, urea cycle capacity and their biochemical assessment. Nutrition Reviews, v. 37, n. 9, p. 273-282, 1979.

20 SPIRES, H. R.; CLARK, J. H. Effect of intraruminal urea administration on glucose metabolism in dairy steers. The Journal of Nutrition, v. 109, n. 8, p. 14381447, 1979.

21 SYMONDS, H. W.; MATHER, D. L.; COLLIS, K. A. The maximum capacity of the liver of the adult dairy cow to metabolize ammonia. The British Journal of Nutrition, v. 46, n. 3, p. 481-486, 1981.

22 SINGER, R. H.; MCCARTY, R. T. Acute ammonium salt poisoning in sheep. American Journal of Veterinary Research, v. 32, n. 8, p. 1229-1238, 1971.

23 ANTONELLI, A. C. Administração de doses padrão e alta de uréia extrusada ou granulada em bovinos: uma análise clínica-toxicológica e laboratorial. 2003. 147 f. Dissertação (Mestrado em Clínica Veterinária) Faculdade de Medicina Veterinária e Zootecnia, Universidade de São Paulo, São Paulo, 2003. 